Doppler-satellite heights above the reference ellipsoid and the GEM 10C geoidal model. A regression line of height above sea level vs. ice thickness proved useful for distinguishing between floating and grounded ice. Deviations from hydrostatic equilibrium of about $10 \mathrm{~m}$ or more were detectable. Application of this criterion has led to detection of several ice rises and ice rumples (Figure 1).

The surfaces of the active ice streams, A and B, are heavily crevassed and their boundaries are marked by chaotic, incoherent bands of surface crevasses, but there are no visible crevasses on ice stream C. However, sounding on the surface of ice stream $C$, using a carrier-free monopulse radar, has revealed numerous crevasses buried at a depth of about $35 \mathrm{~m}$, which corresponds to about 250 years of snow accumulation. This suggests that ice stream $\mathrm{C}$ ceased to be active about 250 years ago.

Crevasses at or near the surface produce a distinctive back-scattered radar return (clutter) that we have used to map the ice streams and their extensions onto the ice shelf. The lack of "clutter" on slowly-moving ice, along with the surface elevation data, has enabled us to extend the mapped boundary of Crary Ice Rise about $70 \mathrm{~km}$ upstream, and to map several other ice rises (Figure 1).

\title{
ICE-SHEET THICKENING OBSERVED BY SATELLITE ALTIMETRY \\ (Abstract)
}

by

H.J. Zwally

(NASA, Goddard Space Flight Center, Greenbelt, Maryland 20771, U.S.A.)

\section{ABSTRACT}

The first set of sequential measurements by two different sets of satellite altimetry data indicate that the Greenland ice sheet, south of $65.1^{\circ}$ north latitude, thickened at the rate of $35 \pm 17 \mathrm{~cm} \mathrm{a}^{-1}$ during 1975 to 1978. The average change in surface elevation was calculated from the elevation differences determined at 525 locations observed by both GEOS-3 and Seasat radar altimeters. The observed thickening is consistent with the $8 \mathrm{~cm} \mathrm{a} \mathrm{a}^{-1}$ thickening previously measured in the accumulation zone, approximately
$900 \mathrm{~km}$ farther north, during conventional, surface, survey methods. The increase in ice thickness suggests a higher precipitation than the long-term average, which is one possible result of a warmer climate in polar regions. The excess ice accumulation, in the $10 \%$ of the Greenland ice sheet observed, is estimated to be $53 \mathrm{~km}^{3} \mathrm{a}^{-1}$, which is equivalent to a sea-level reduction of $0.15 \mathrm{~mm} \mathrm{a}^{-1}$. Additional, high-precision, sequential, altimetric measurements could be used to determine the overall mass balance of the Greenland and Antarctic ice sheets. 